\title{
Experimental Study on the Damage Characteristics of Polymer Slabs Subjected to Air Contact and Close-In Explosions
}

\author{
Zhidong Liu, ${ }^{1,2}$ Xiaohua Zhao $\mathbb{D}^{1,2,3}$ Hongyuan Fang $\mathbb{D}^{1,2}$ Xueming Du $\mathbb{D}^{1,2}$ \\ Binghan Xue $\mathbb{D}^{1,2}$ and Zhaonan $\mathrm{Li}^{4}$ \\ ${ }^{1}$ School of Water Conservancy Engineering, Zhengzhou University, Zhengzhou 450001, China \\ ${ }^{2}$ National Local Joint Engineering Laboratory of Major Infrastructure Testing and Rehabilitation Technology, \\ Zhengzhou 450001, China \\ ${ }^{3}$ Hubei Key Laboratory of Construction and Management in Hydropower Engineering, China Three Gorges University, \\ Yichang 443002, China \\ ${ }^{4}$ Faculty IV Electrical Engineering and Computer Science, Technical University Berlin, Berlin 13353, Germany
}

Correspondence should be addressed to Xiaohua Zhao; zhaoxh2014@126.com and Hongyuan Fang; zhaoxh@zzu.edu.cn

Received 13 May 2021; Accepted 15 July 2021; Published 26 July 2021

Academic Editor: Yunzhong Jia

Copyright (c) 2021 Zhidong Liu et al. This is an open access article distributed under the Creative Commons Attribution License, which permits unrestricted use, distribution, and reproduction in any medium, provided the original work is properly cited.

As a new antiseepage reinforcement material, polyurethane grouting material has been widely studied in terms of its static mechanical properties. However, research on its dynamic mechanical properties is relatively rare. In this research, considering the influence of the explosive charge weight, the air contact and close-in explosion experiments of polymer slabs were carried out. The failure mode and damage spatial distribution characteristics of polymer slabs were explored. Pressure time history curve of air shock wave was obtained using an air shock wave tester. The influence of polymer slabs on the propagation of air explosion shock wave was compared and analyzed. The results show that, under the air contact explosion, the polymer slab mainly suffers local damage, while under close-in explosion, overall damage is the main damage mode. With the increase of the explosive charge weight, the failure mode of the polymer slab transits from surface crack and slight spalling to local and whole crushing.

\section{Introduction}

Polyurethane is mainly composed of isocyanate and polyol polymerization, which has a series of advantages [1], such as rapid and adjustable reaction, high expansion rate, impermeability and waterproofness, and no environmental pollution. Hence, it has outstanding effect on solving specific complex engineering disaster problems, such as improving the properties of soft soil and increasing its strength [2]. Polyurethane has been widely used in high-speed railway unballasted track [3], underground pipeline [4, 5], dam, cutoff wall [6], tunnel, highway [7], airport runway [8], and other infrastructure seepage rescue and rapid repair.

Researchers have carried out relevant investigations on the static properties of polymer, such as compressive strength and shear properties. In addition, they have also carried out research on its properties of high expansion and diffusion, strong permeability resistance, rapid curing, durability, and environmental protection [9]. For example, Shi et al. [10] explored the effect of temperature on the compressive strength and volume change of polyurethane grouting materials through uniaxial compression test; $\mathrm{Li}$ et al. [1] carried out uniaxial compression test on polyurethane grouting materials to study the influence of density and size of polyurethane samples on compressive strength. The direct shear behavior of polyurethane bentonite interface under different normal stress, water content, and density was studied [11]; Beverte et al. [12] tested the shear strength and modulus of polyurethane material using a selfmade axial clamping tensile tester; Fang et al. [13] explored the interface between polyurethane material and concrete using a scanning electron microscope and a series of direct shear tests. Niedziela et al. [14] calculated and analyzed the uneven expansion of polyurethane materials; Hao et al. [15] 
studied the diffusion process of polyurethane slurry in cracks through numerical analysis and experiments; Wang et al. [16] explored the permeability resistance of polyurethane grouting materials through experiments; Chen et al. [17] studied the durability of porous polyurethane mixture. However, the above research is mainly carried out on the static mechanical properties of polyurethane grouting materials, and there are few studies focusing on the dynamic mechanical properties, especially the damage characteristics under explosive impact load.

Field explosion test is widely used in the study of dynamic mechanical properties of concrete slabs, steel plates, bridges, and other structures. For example, Wang et al. [18] studied the damage characteristics and damage modes of unidirectional square reinforced concrete slabs under different TNT initiating charges through four groups of field explosion tests; Zhao et al. [19] explored the damage characteristics of concrete slabs under air and underwater contact explosion through field explosion tests and considered the boundary conditions, reinforcement, charge shape, and charge quality. The dynamic response of reinforced concrete slabs subjected to $500 \mathrm{~g}$ TNT contact explosion was studied by Dua and Braimah [20]. Gao et al. [21] designed and manufactured one-way sea-sand seawater concrete slabs reinforced with basalt fiber reinforced plastic (BFRP) bars and explored the damage mode and antiexplosion characteristics of one-way sea-sand seawater concrete slabs reinforced with basalt fiber reinforced plastic (BFRP) bars under air close-in explosion through field explosion test. Li et al. [22] explored the failure mode and antiknock performance of steel mesh reinforced concrete slab under contact explosion through field explosion test. Chen et al. [23] investigated the failure mode, damage characteristics, and antiknock performance of autoclaved aerated concrete (AAC) slab strengthened with polyurea coating under close-in explosion through field explosion test; Yang et al. [24] explored the damage mode of reinforced concrete slab under air and underwater contact explosion through field explosion test. Zhuang et al. [25] studied the dynamic response and damage mode of reinforced concrete cylinder under underwater explosion through field explosion test. Yang et al. [26] proposed an EDZ rock mass properties estimation method based on the generalized Hoek-Brown failure criterion and variable disturbance factor, which is used to quickly estimate the rock mass properties of EDZ change when the blasting method is used to excavate the slope in the rock mass. Furthermore, Yang et al. [27] monitored the vibration data at the tunnel blasting excavation site, analyzed and obtained the vibration characteristics of the tunnel surface and surrounding rock, and verified the site survey results using a three-dimensional dynamic finite element model. It is worth noting that the above field explosion tests are mainly carried out for concrete materials, while the field explosion tests for polymer slabs made of polyurethane materials are relatively less.

In this research, the air contact and close-in explosion tests of square polymer slabs were carried out, and the damage characteristics and dynamic response of polymer slabs were explored. The shock wave experimental data of the upper and lower sides of the slab could provide experimental basis for the antiknock performance research of polymer slab.

\section{Experimental Setup}

2.1. Specimen Preparation. In this paper, six polymer slabs with the same density, mass, volume, and shape were made by using self-made injection mould. Nonaqueous reactive two-component foaming polyurethane was used as polymer material. Isocyanate and polyol were injected into the steel model with a grouting gun at a mass ratio of $1: 1$, and gelation reaction and foaming reaction occurred [13]. The density of polymer slab is $0.2 \mathrm{~g} / \mathrm{cm}^{3}$ and the density is controlled by grouting quality. Polyurethane grouting material with this density is widely used in engineering applications such as dyke seepage prevention, so we choose $0.2 \mathrm{~g} / \mathrm{cm}^{3}$ as the density of our polymer slabs. The length and width of the polymer slab are $50 \mathrm{~cm}$ and the thickness is $6 \mathrm{~cm}$. During the foaming process, the swelling force of polyurethane material develops rapidly within 35 seconds after pouring, and the swelling force increases exponentially with the increase of foam density. The foam gradually solidified in $10 \mathrm{~min}$, and the strength reached a stable level after 1 hour. The samples were placed at $20^{\circ} \mathrm{C}$ and $40 \%$ relative humidity for 24 hours and then demoulded and taken out to make the polymer slab. The polymer slab samples have the typical characteristics of plastic materials $[1,11]$. In addition, Li et al. [1] studied the mechanical properties of polyurethane grouting materials under quasistatic conditions and gave the static mechanical parameters of polyurethane grouting materials of different densities under uniaxial compression tests, such as stress-strain curve, Young's modulus, secant modulus, and yield strength. And an important conclusion is obtained: the mechanical properties of low-density polyurethane $\left(\leq 0.3 \mathrm{~g} / \mathrm{cm}^{3}\right)$ are hardly affected by geometric dimensions. Figure 1 shows the specimen preparation process.

2.2. Equipment. During the test, the Blast-PRO impact tester was used to monitor the air shock wave generated by the explosion load, as shown in Figure 2(a). The vibration acceleration of the polymer slab in $X, Y$, and $Z$ directions was measured with the Blast-Cloud blasting vibration tester, as shown in Figure 2(b).

2.3. Explosion Load. The rock emulsion explosive with density of $1.05 \mathrm{~g} / \mathrm{cm}^{3}$, detonation velocity of $4.2-5.0 \mathrm{~km} / \mathrm{s}$, and briskness of $12 \mathrm{~mm}$ was the used test, as shown in Figure 3(a). In order to avoid mass loss during weighing and explosive placement, thin plastic bags were used to wrap the explosives. It should be noted that the shape of the explosive is not an absolute cube or cuboid. This is because rock emulsion explosives have good fluidity, and the weight of the explosive test charge is very small (only 15-50 g), and it is difficult to ensure that the explosive charge has a regular shape. However, we used plastic film to wrap the explosives so that the shape of the explosives used in each group of tests 


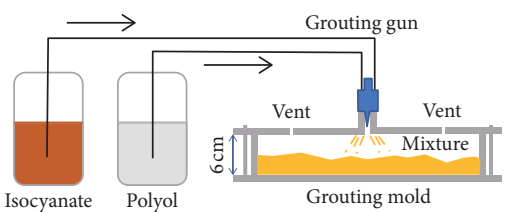

(a)

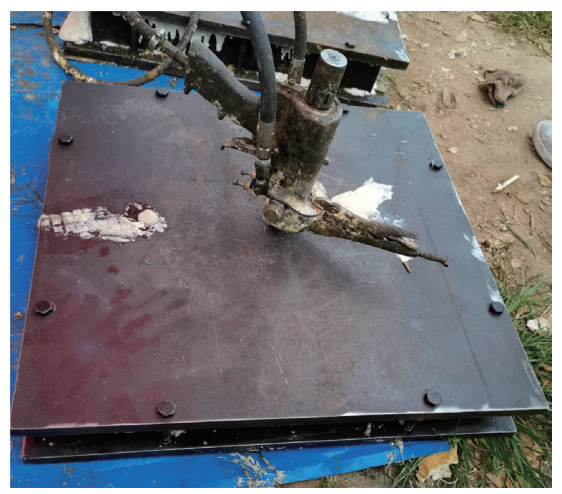

(b)

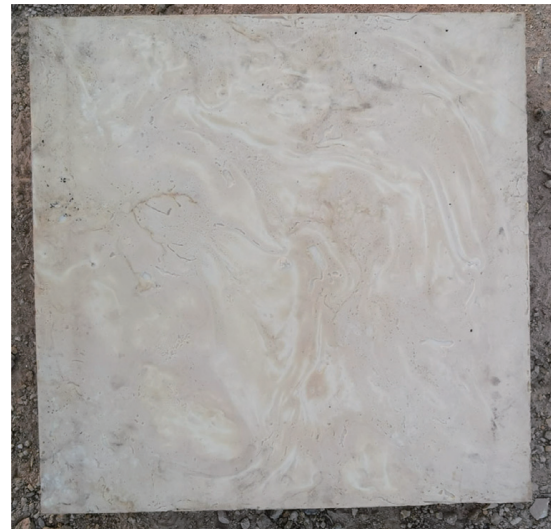

(c)

FIGURE 1: The preparation process of the specimens. (a) Grouting. (b) Grouting completed. (c) Specimens.

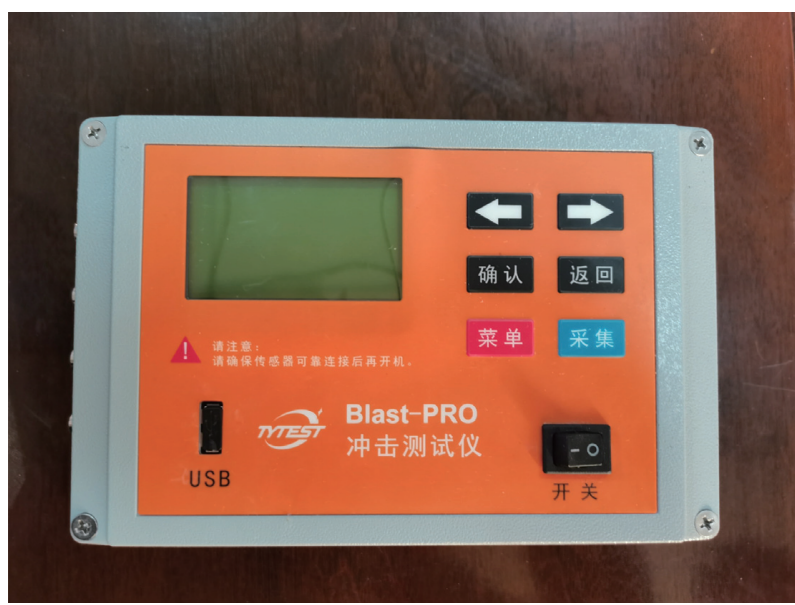

(a)

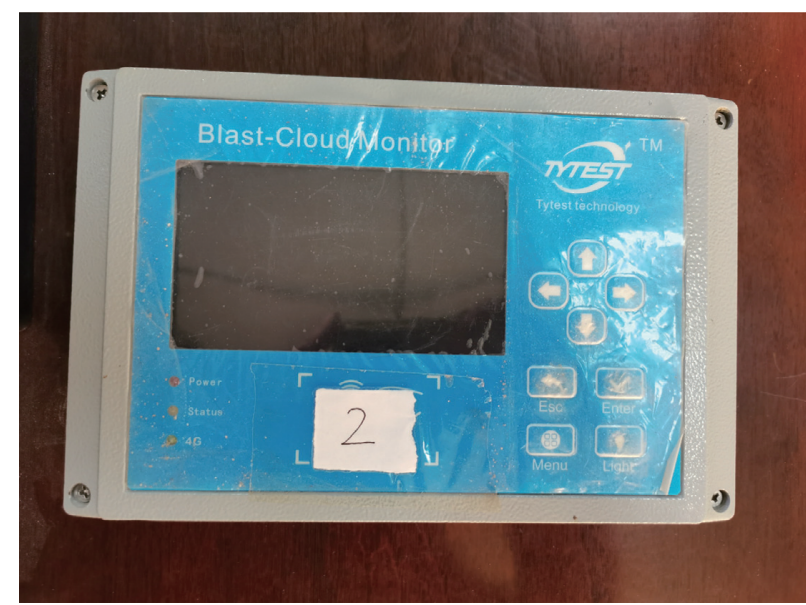

(b)

FIgURE 2: Equipment. (a) Blast-PRO. (b) Blast-Cloud monitor.

was basically spherical, which greatly reduced the impact of the shape of the explosives. The accuracy of the electronic balance used for weighing is $0.01 \mathrm{~g}$. The charge was initiated with a nonelectric detonator, as shown in Figure 3(b).

2.4. Experiment Device. In order to reduce the impact of the reflection of shock wave on the ground on the test results, a special steel frame was used to assemble a test device with a height of $1.5 \mathrm{~m}$, which was placed on the flat ground (see Figure 4). The polymer slab was fixed on the welded iron bracket, and steel slabs were inserted between the two boundaries of the polymer slab and the iron bracket, which were fixed with special bolts in advance, to provide approximate fixed boundary conditions for the specimen. The welded iron support was fixed on the erected steel frame. Four air shock wave sensors were arranged on both sides of the upper and lower surfaces of the polymer slab in order, and two probes were arranged on each side, respectively, $80 \mathrm{~cm}$ and $100 \mathrm{~cm}$ away from the explosion facing surface of the polymer slab, which were numbered as \# 1, \#2, \#3, and \#
4 from top to bottom. The air shock wave sensor used in our test has good sensitivity and test accuracy, and a slight tilt will not affect its receiving shock wave signal. In addition, we will check whether the sensor is tightly fixed before each test, so as to prevent it from generating a large tilt that may affect the measurement of the test data. The sensor of the blasting vibration meter was fixed in the polymer slab with bolts. In the case of close-in explosion, the charge was suspended above the center of the slab, and the distance between the explosion centers was $20 \mathrm{~cm}$. The detonator for initiation was placed in the center of the charge. Figure 5 is a simplified diagram of the experiment device.

2.5. Experiment Grouping. Six identical polymer slabs were labeled A0, B0, B1, B2, B3, and B4, respectively. Among them, $\mathrm{A} 0$ and $\mathrm{B} 0$ are compared to analyze the influence of the burst distance on the failure mode and damage characteristics. From B0 to B4, the explosive charge weight has been increasing, to explore the influence of the explosive charge weight on the failure characteristics of polymer slab 
under the action of air close-in explosion. The boundary conditions of the polymer slabs in the six tests are all the same, i.e., fixed boundary. The specific grouping of the experiment is shown in Table 1.

\section{Results and Analysis}

3.1. The Influence of StandoffDistance. The relative positions of explosive and polymer slab in air contact and close-in explosion are given in Figure 6.

The test results of polymer slab A0 are shown in Figure 7. It can be seen from the figure that, under the action of contact explosion, the polymer slab is mainly characterized by local punching, collapse, and spalling on bottom surface.

It can be seen from Figure 7 that, after the test, the central area of the polymer slab A0 is penetrated; a hole with a diameter of about $15 \mathrm{~cm}$ is formed on the top surface of the slab, and a damage area with a diameter of about $20 \mathrm{~cm}$ is formed on the center of bottom surface. Besides, the polymer in the damage area peels off. The reason is that, under the action of contact explosion, the high-pressure shock wave generated by explosion directly acts on the top surface of the polymer slab, and the generated compressive stress is higher than the dynamic compressive strength of the polymer. Therefore, firstly, a crater is formed on the top surface. After the shock wave pressure propagates to the interior of the polymer slab, it propagates to the bottom in the form of compression wave, and the strong tensile wave is reflected on the bottom surface of the slab. It causes the bottom surface collapse and spalling damage, so that the middle part of the polymer slab results forms a hole.

Figure 8 shows the test results of specimen B0 subjected to close-in explosion. Compared with the specimen A0, the standoff distance changes from $0 \mathrm{~cm}$ to $20 \mathrm{~cm}$, and other conditions remain unchanged.

It can be seen from Figure 8 that the damage of polymer slab B0 under close-in explosion is more serious than that under air contact explosion. One of the nonfixed edges of the polymer slab is completely broken, the maximum length of the damage area of the top surface is about $40 \mathrm{~cm}$, and the polymer spalling damage is serious on the bottom surface. The maximum length of the damage area of the bottom surface is about $30 \mathrm{~cm}$, and there are two shallow pits formed by the polymer spalling in the top surface. The reason might be that when the explosive explodes in the air, it can strongly compress the air to form a shock wave. After the shock wave reaches the top surface of the slab, the resulting compressive stress is higher than the dynamic compressive strength of the polymer slab, resulting in the damage on the top surface. Then, the compression wave is transmitted into the slab through the air; as it propagates to the bottom surface of the slab, it reflected to a strong tensile wave. The tensile stress produced is higher than the dynamic tensile strength of the polymer, which eventually leads to the collapse of the bottom surface and the spalling of some polymers into pits. Therefore, under the action of close-in explosion, the polymer slab is damaged as a whole, and the damage degree of specimen $\mathrm{B} 0$ is more serious than that of specimen $\mathrm{A} 0$.
Figure 9 shows the time history curves of shock wave pressure measured in contact explosion test. During the air contact explosion, the time history curve of shock wave pressure is divided into positive pressure zone and negative pressure zone (with the standard atmospheric pressure as the boundary).

According to the time history curve of shock wave pressure in Figure 9(a), when $t=0.47 \mathrm{~ms}$ after explosion, the air shock wave propagates to the \#1 measuring point. And the pressure reaches the peak value instantly; its overpressure peak value is $0.133 \mathrm{MPa}$. Then it decays exponentially to the standard atmospheric pressure, and then it enters the negative pressure area, and the decay rate becomes slower and slower. As shown in Figure 9(b), the air shock wave reaches the symmetrically set \#4 measuring point at $t=0.58 \mathrm{~ms}$, and the peak overpressure is only $0.053 \mathrm{MPa}$. From the comparison of \#4 and \#1 measuring points, the peak overpressure at \#1 measuring point is 2.51 times of that at \#4. This might cause the damage and breakage of polymer slab, and most of shock wave energy is consumed quantity.

Figure 10 is the time history curve of shock wave pressure measured at the same distance from the upper and lower sides of the polymer board B0.

It can be seen from Figure 10 that, under the action of close-in explosion, the peak overpressure measured using \#4 sensor is $0.1 \mathrm{MPa}$, which is far lower than $0.296 \mathrm{MPa}$ measured using \#1 sensor, and the latter is 2.96 times of the former. This shows that the polymer slab has a good weakening effect on the propagation of blasting shock wave in air.

Comparing Figures 9 and 10, under contact explosion, the difference between \#1 and \#4 peaks is $0.0793 \mathrm{MPa}$, while for close-in explosion, the difference is $0.2019 \mathrm{MPa}$, which is 2.55 times of the former. Therefore, compared with the contact explosion with the same amount of explosive, the weakening effect of the polymer slab on the air shock wave is stronger in the close-in explosion.

Figure 11 shows the vibration acceleration curves of A0 and $\mathrm{B} 0$ in $X, Y$, and $Z$ directions. The maximum acceleration values of $\mathrm{A} 0$ in $X, Y$, and $Z$ directions are $8.6 \mathrm{~g}, 9.8 \mathrm{~g}$, and $9.9 \mathrm{~g}$, respectively. These values of $\mathrm{B} 0$ are basically the same, which are $7.2 \mathrm{~g}, 9.1 \mathrm{~g}$, and $10.4 \mathrm{~g}$, respectively.

Through the explosive tests of A0 and B0, under same conditions, the damage degree of polymer slab under the action of close-in explosion is more serious than that of contact explosion. Therefore, more attention should be paid to the damage mode and dynamic response of polymer slab under the action of close-in explosion.

3.2. The Influence of the Explosive Charge Weight. In order to explore the influence of the explosive charge weight on the damage performance of polymer slabs under the action of close-in explosion, explosive charge weights of $15 \mathrm{~g}, 25 \mathrm{~g}$, $30 \mathrm{~g}$, and $50 \mathrm{~g}$ are carried out on specimens B1, B2, B3, and $\mathrm{B} 4$, respectively. The explosive distance is controlled as $20 \mathrm{~cm}$, and other test conditions are the same. The damage results are shown in Figures 12 15. 


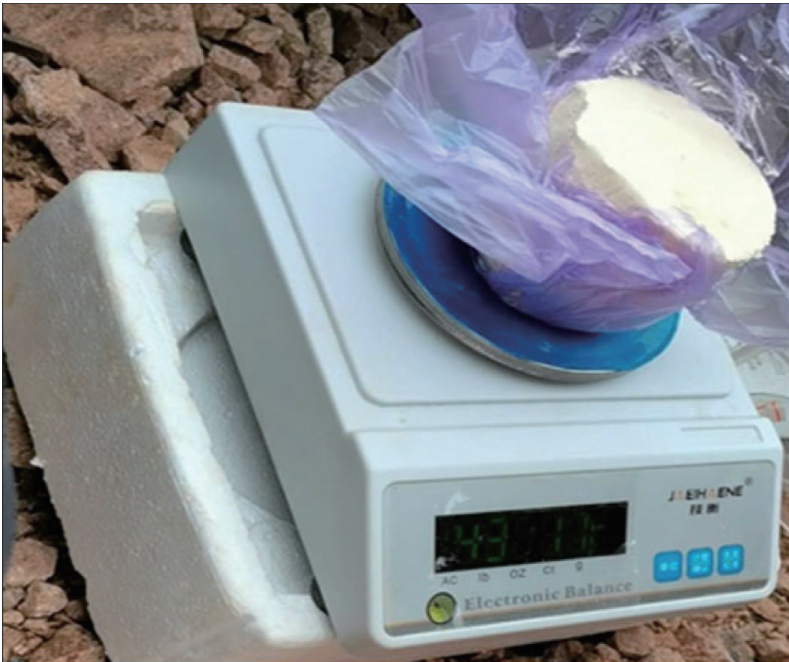

(a)

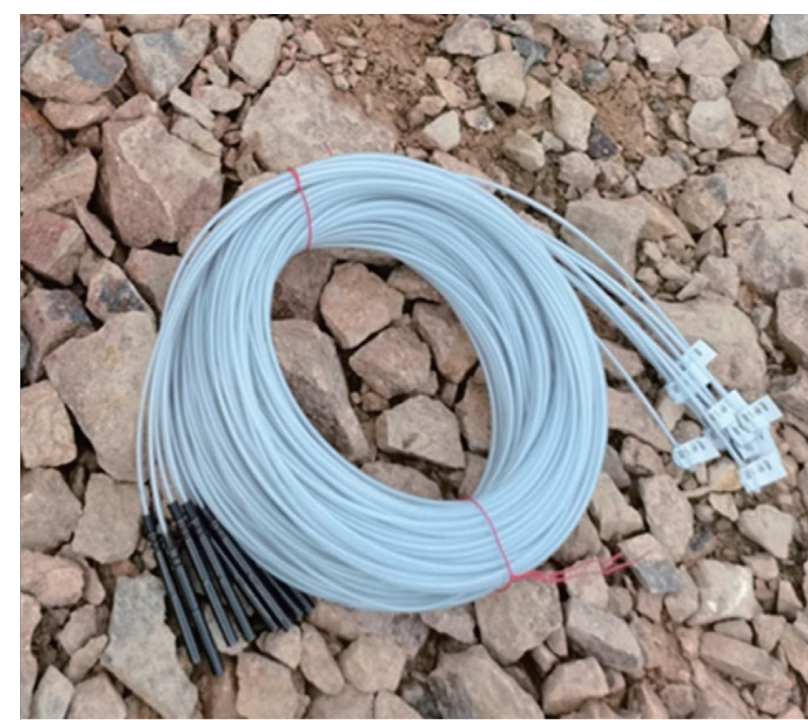

(b)

Figure 3: Explosive charge and detonator. (a) Rock emulsion explosive. (b) Detonator.

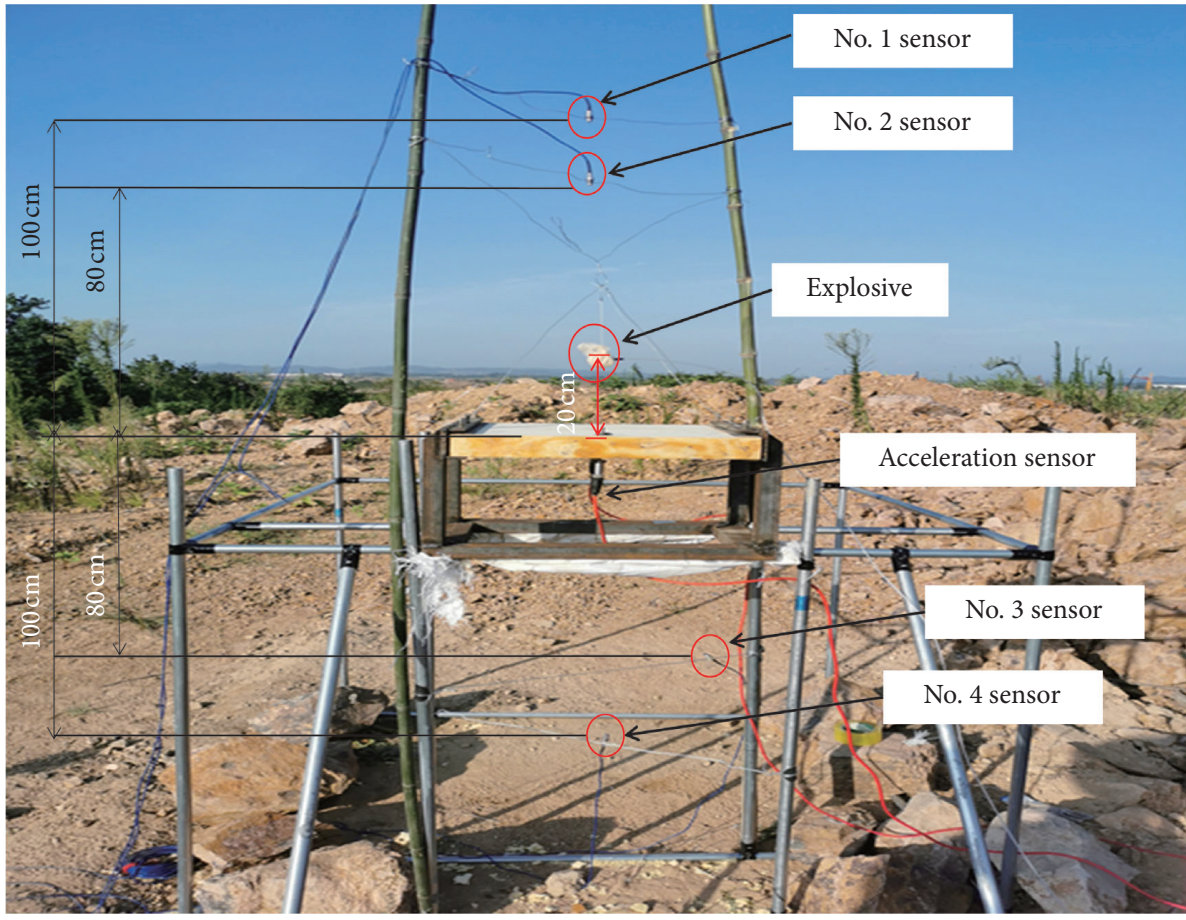

FIgURe 4: Experiment device.

As shown in Figure 12, the damage degree of specimen $\mathrm{B} 1$ is lighter than that of specimen B0, due to the explosive quality which decreases to $15 \mathrm{~g}$. The polymer in the center of the bottom surface peels off to form a shallow pit with a diameter of $2 \mathrm{~cm}$, and there is an obvious longitudinal crack in the middle of the bottom surface.

As the explosive quality increases to $25 \mathrm{~g}$, the damage degree of the polymer slab (specimen B2) is more serious than that of specimens B0 and B1, as shown in Figure 13. It is observed that the polymer slab breaks along the two fixed edges, resulting in two fracture surfaces approximately parallel to the fixed edge. This might because, under the downward explosive impact, serious shear action occurs at the contact part between the two fixed edges and the steel frame, and the shear stress produced is far greater than the dynamic shear strength of the polymer slab. Therefore, the polymer slab breaks, and the fracture surface is parallel to the two fixed boundaries of the slab. In addition, spalling occurred on the bottom surface due to the tensile shock wave action. 


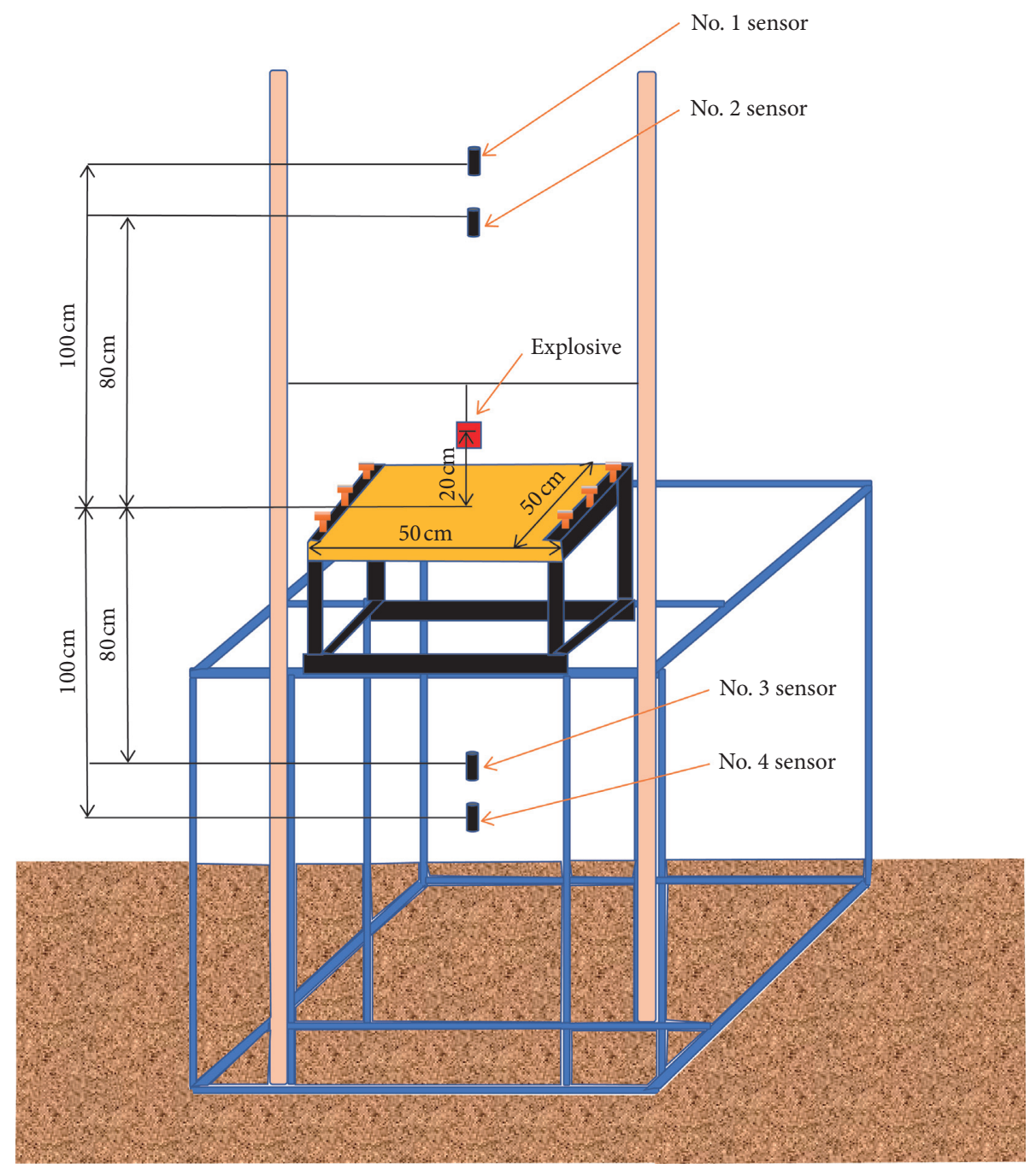

FIgURE 5: Simplified picture of the explosion experiment device.

TABLe 1: Experimental program.

\begin{tabular}{lccccc}
\hline Specimen numbers & $\begin{array}{c}\text { Rock emulsion } \\
\text { explosive }(\mathrm{g})\end{array}$ & $\begin{array}{c}\text { Standoff } \\
\text { distance }(\mathrm{cm})\end{array}$ & Detonation mode & Boundary conditions & Dimensions $(\mathrm{cm} \times \mathrm{cm} \times \mathrm{cm})$ \\
\hline A0 & 20 & 0 & Nonelectric detonator & Fixed & $50 \times 50 \times 6$ \\
B0 & 20 & 20 & Nonelectric detonator & Fixed & $50 \times 50 \times 6$ \\
B1 & 15 & 20 & Nonelectric detonator & Fixed & $50 \times 50 \times 6$ \\
B2 & 25 & 20 & Nonelectric detonator & Fixed & $50 \times 50 \times 6$ \\
B3 & 30 & 20 & Nonelectric detonator & Fixed & $50 \times 50 \times 6$ \\
B4 & 50 & 20 & Nonelectric detonator & Fixed & $50 \times 50 \times 6$ \\
\hline
\end{tabular}

If the charge weight is still increased to $30 \mathrm{~g}$, the damage degree of specimen B3 continues to increase, as shown in Figure 14. Most of the middle part of the specimen B3 has been basically broken, and the uncracked part is divided into three large pieces. Two broken pieces along the fixed boundary and a small piece are connected with the right boundary crack. Moreover, there is a longitudinal fracture surface about $30 \mathrm{~cm}$ long between them.
Under the impact with explosive charge equal to $50 \mathrm{~g}$, the damage degree of B4 is very serious. As given in Figure 15, almost all the polymer slabs are destroyed to small pieces except for the left and right fixed boundary parts.

As shown in Figures 16 18, typical time history curves of air shock wave pressure measured using \#1 and \#4 sensors in three groups of tests with the explosive charge weights of $15 \mathrm{~g}, 30 \mathrm{~g}$, and $50 \mathrm{~g}$ are given. The wave forms of the three 

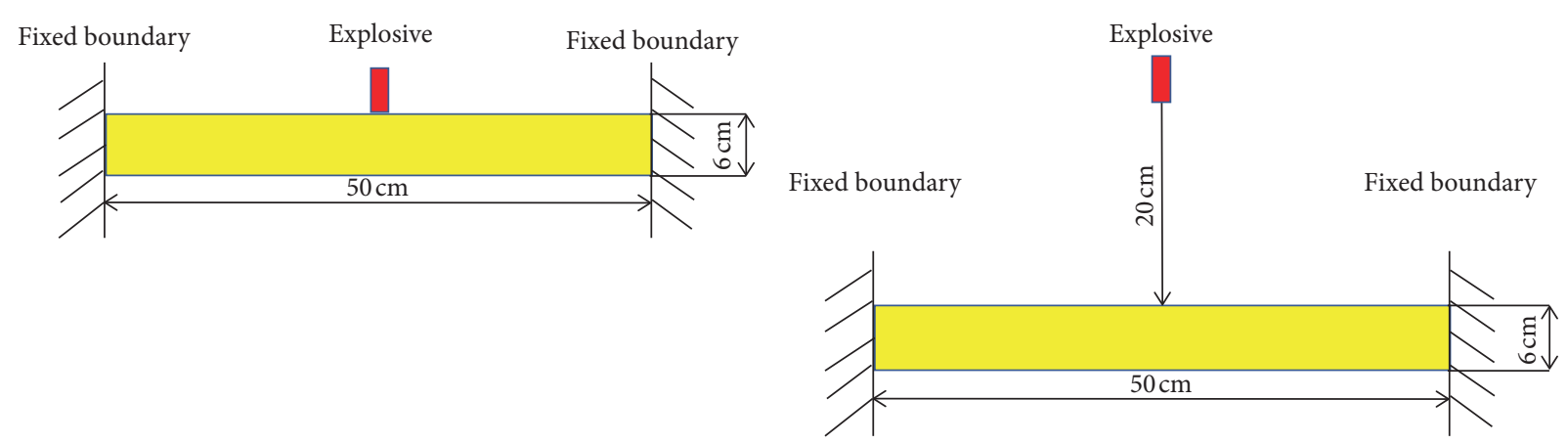

(a)

(b)

Figure 6: Simplified diagram of (a) air contact and (b) close-in explosion.

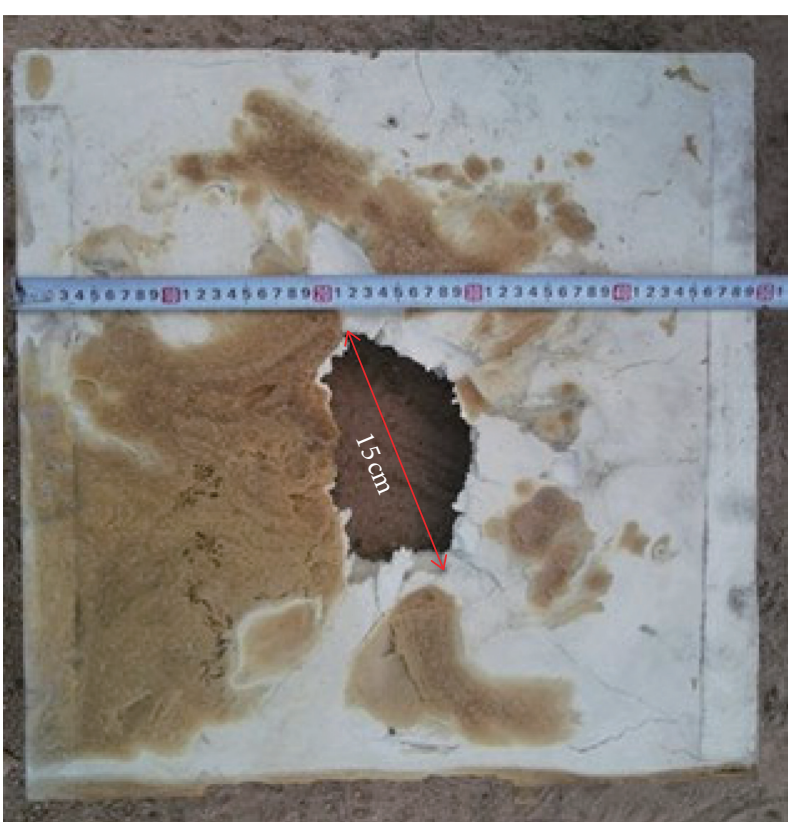

(a)

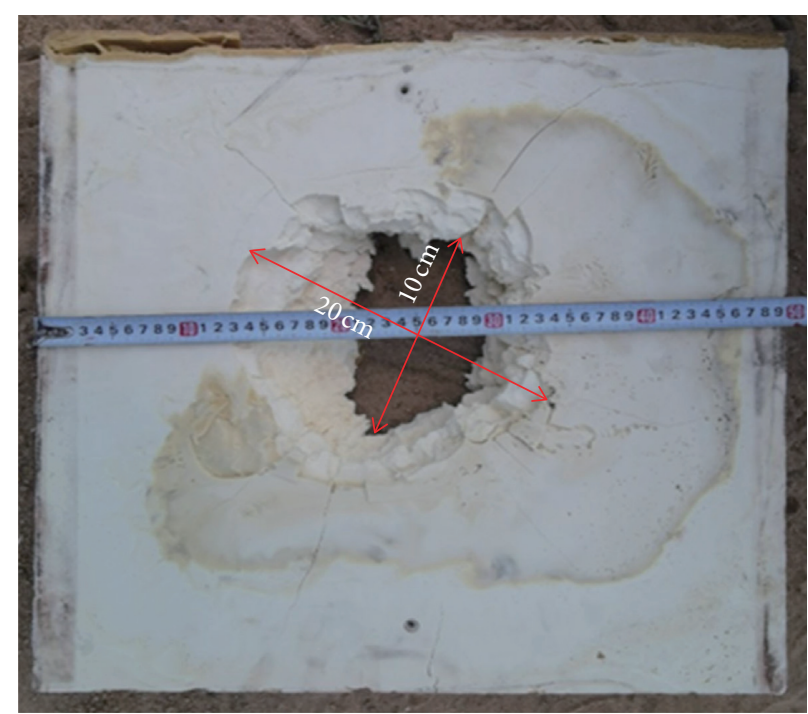

(b)

Figure 7: Test results of polymer slab A0 (contact explosion). (a) Top surface. (b) Bottom surface.

groups of air shock waves are similar, which can be divided into positive pressure zone and negative pressure zone (with the standard atmospheric pressure as the boundary).

As shown in Figure 19, the peak pressure values measured using \#1, \#2, \#3, and \#4 sensors under different charge mass are given.

For the explosive quality of $15 \mathrm{~g}, 30 \mathrm{~g}$, and $50 \mathrm{~g}$, the peak pressures obtained in \#1 sensor are $0.0925 \mathrm{MPa}, 0.4426 \mathrm{MPa}$, and $0.7183 \mathrm{MPa}$, respectively. The peak pressure at \#1 measuring point increased rapidly as the increase of explosive quality. However, for the peak pressure in \#4 sensor, they is only $0.0407 \mathrm{MPa}, 0.1503 \mathrm{MPa}$, and $0.1987 \mathrm{MPa}$. The peak pressures obtained in \#4 measuring point are small and increase slowly compared to that in \#1 measuring point. This might be because the polymer slab has a certain weakening effect on the propagation of shock wave under close-in explosion.

In order to describe the damage results of the polymer slab specifically and conveniently, the residual areas of the polymer slabs after explosion field tests with different charge weight are given in Figure 20.

When the explosive charge weight is $15 \mathrm{~g}$, specimen $\mathrm{B} 1$ is basically intact, while as the explosive charge weight increases to $30 \mathrm{~g}$, the residual area of specimen B3 is only about half of the original area. If the explosive charge weight continues to increase to more than $30 \mathrm{~g}$, the residual area of the polymer slab is smaller, which indicates that the specimen has been basically destroyed. 


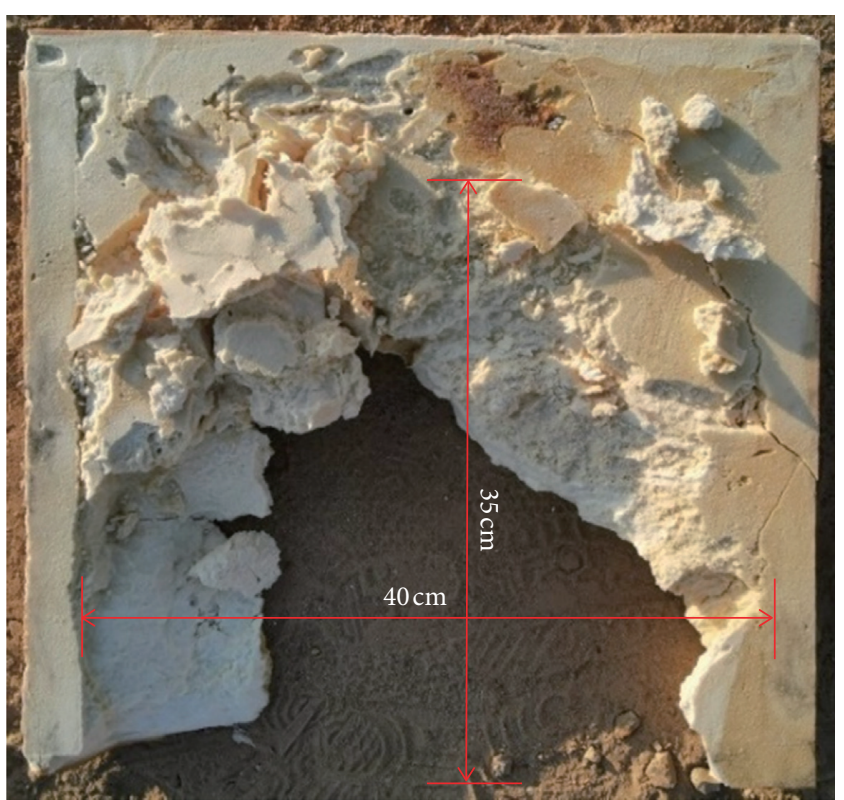

(a)

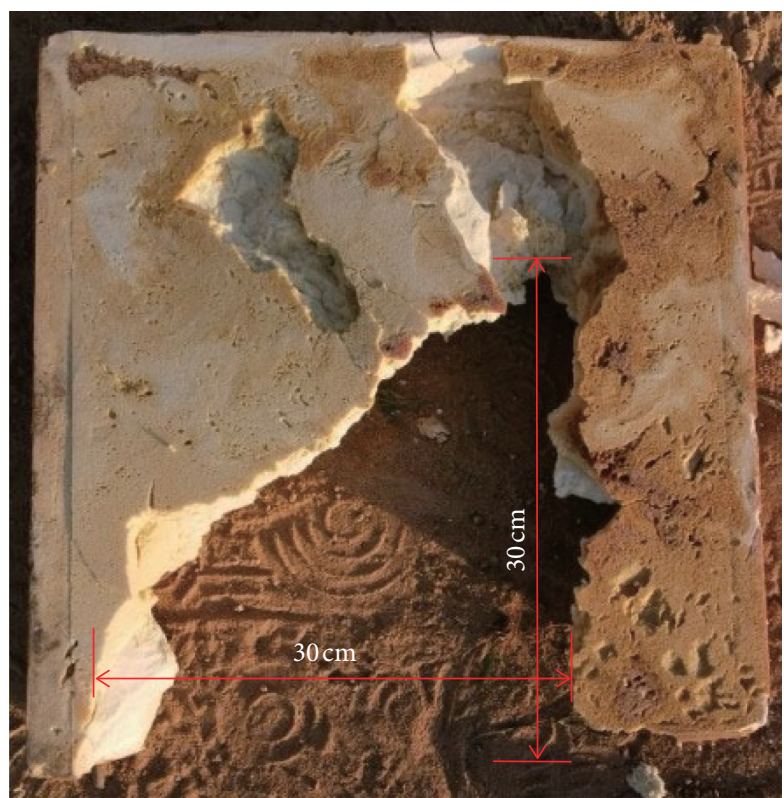

(b)

FIgURE 8: Test results of polymer slab B0 (close-in explosion). (a) Top surface. (b) Bottom surface.

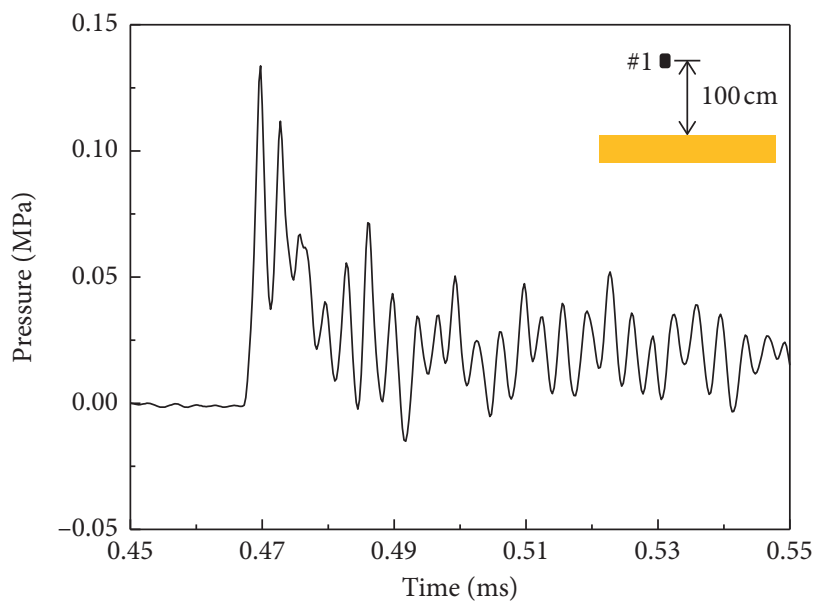

(a)

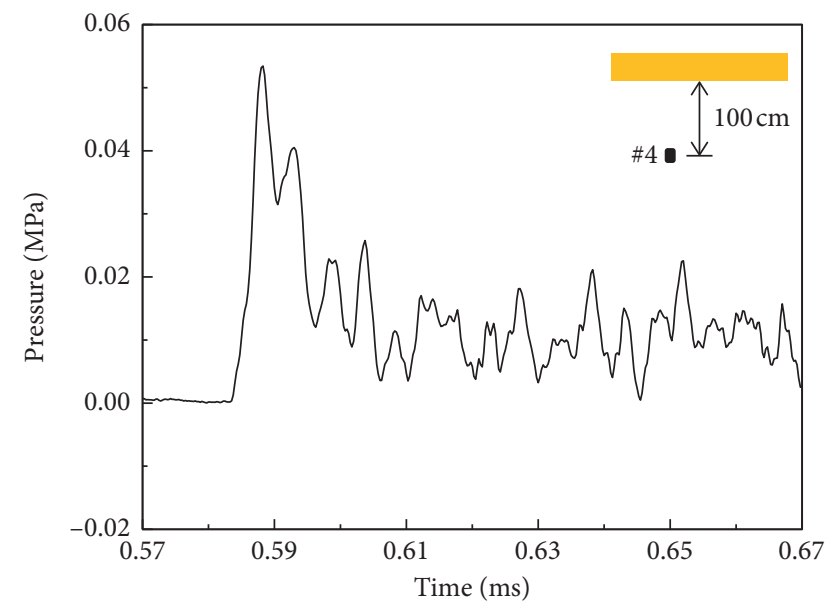

(b)

FIgURE 9: Time history curves of air shock wave pressure of A0. Air shock wave measured using (a) sensor \#1 and (b) sensor \#4.

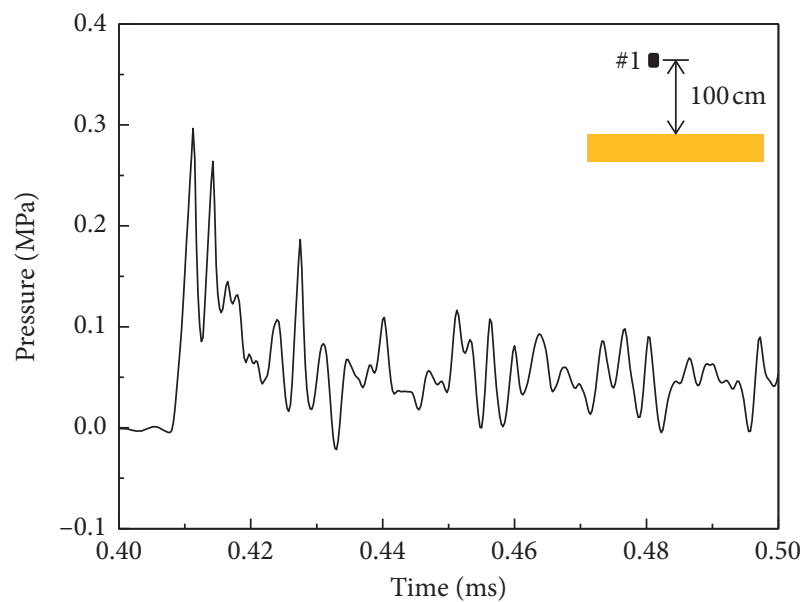

(a)

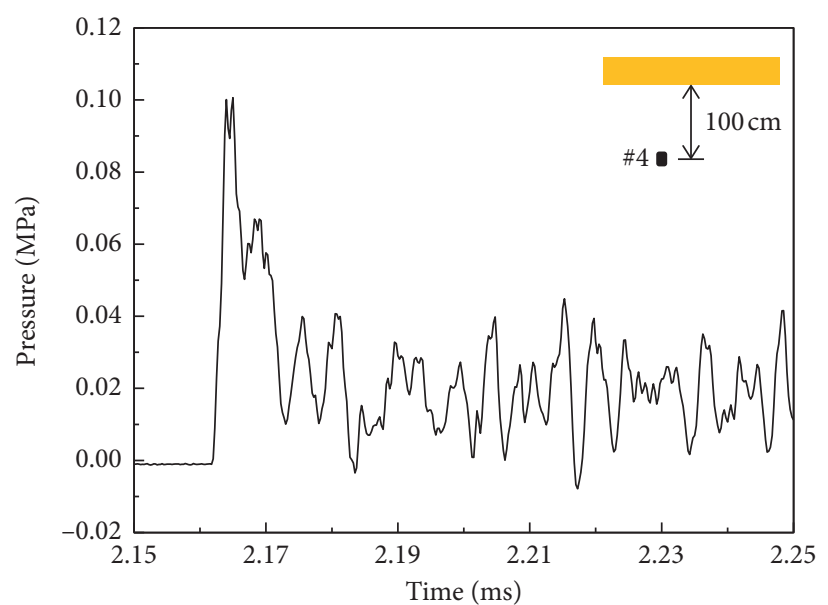

(b)

Figure 10: Time history curves of air shock wave pressure of B0. Air shock wave measured using (a) sensor \#1 and (b) sensor \#4. 


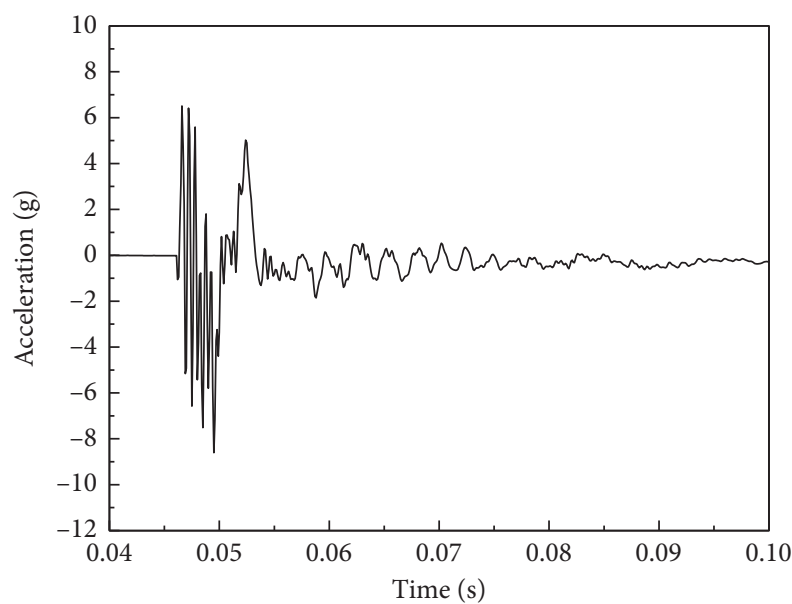

(a)

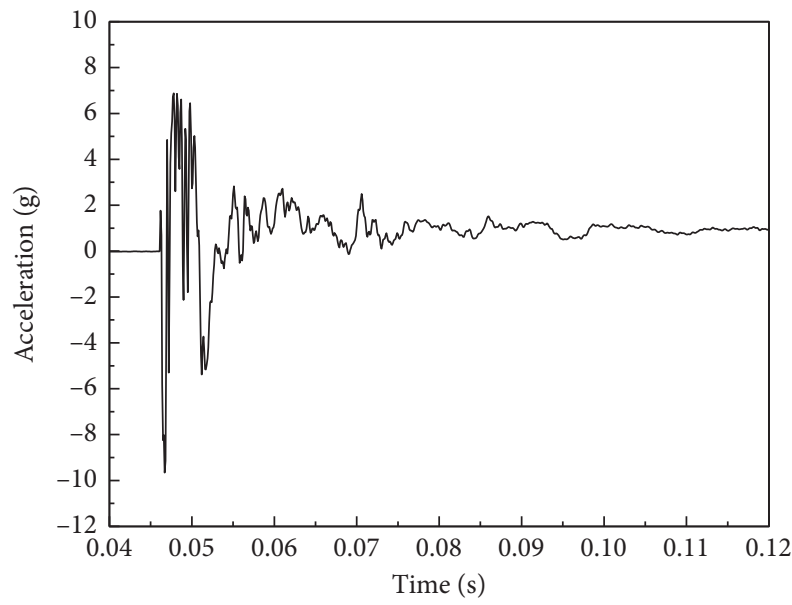

(c)

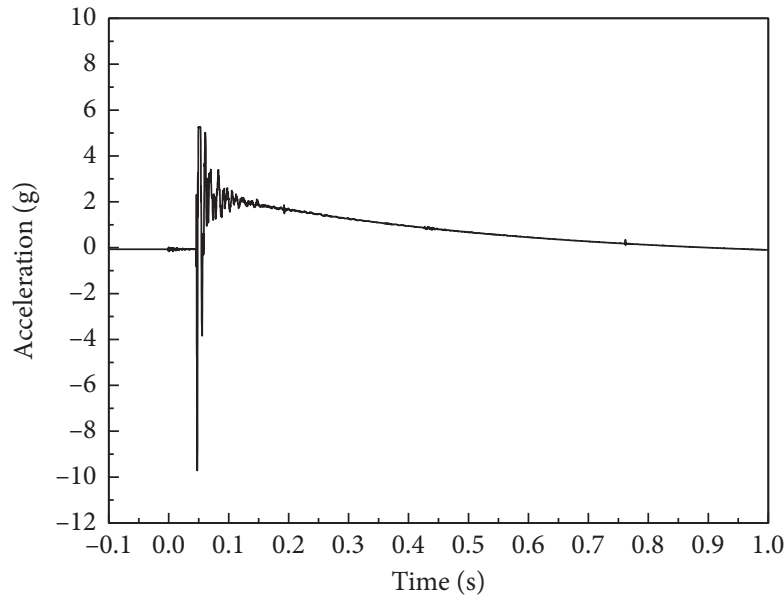

(e)

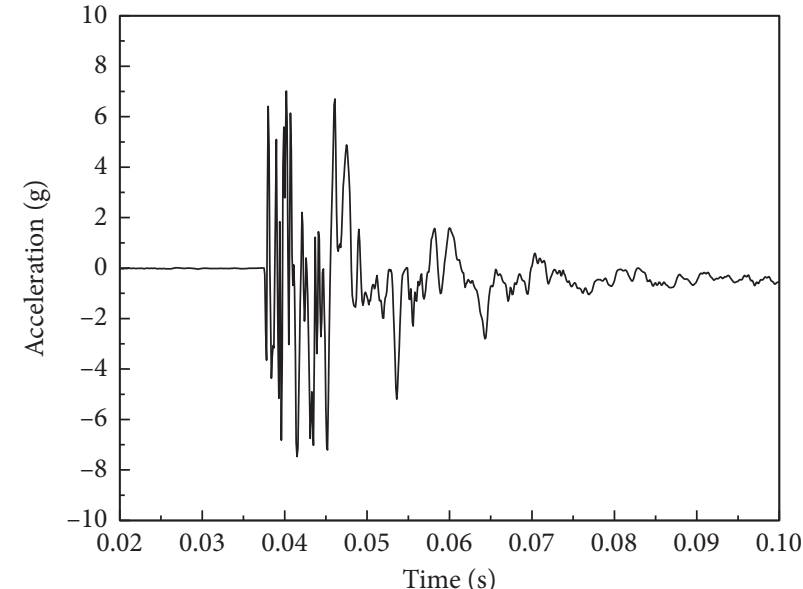

(b)

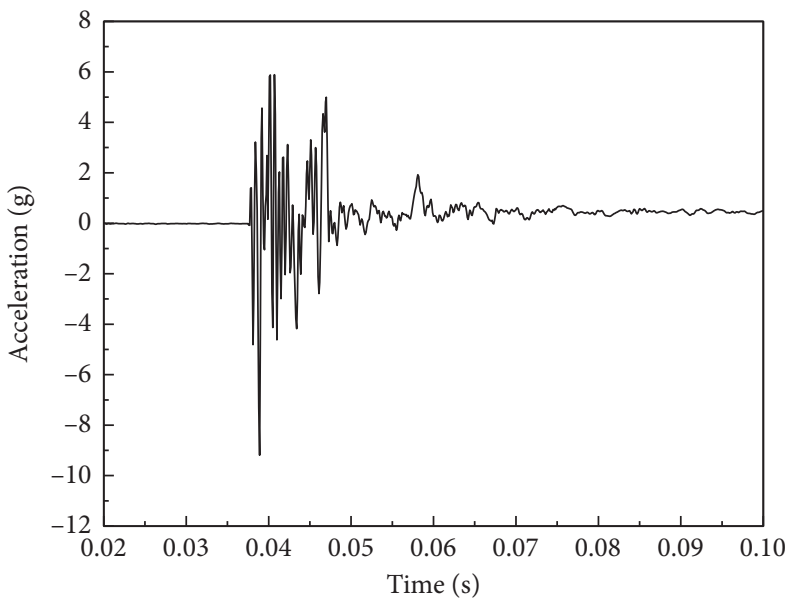

(d)

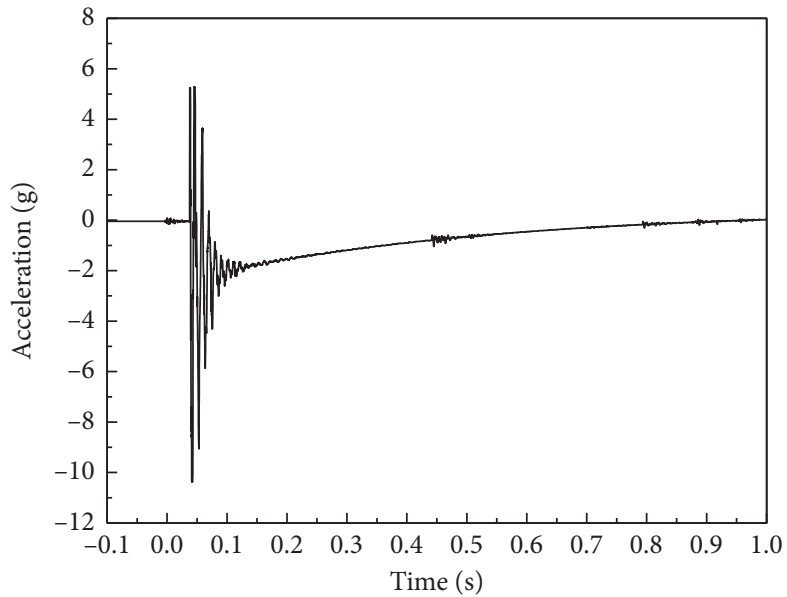

(f)

FIGURE 11: Comparison of vibration acceleration between A0 and B0. (a) $X$ direction of A0. (b) $X$ direction of B0. (c) $Y$ direction of A0. (d) $Y$ direction of B0. (e) $Z$ direction of A0. (f) $Z$ direction of B0. 


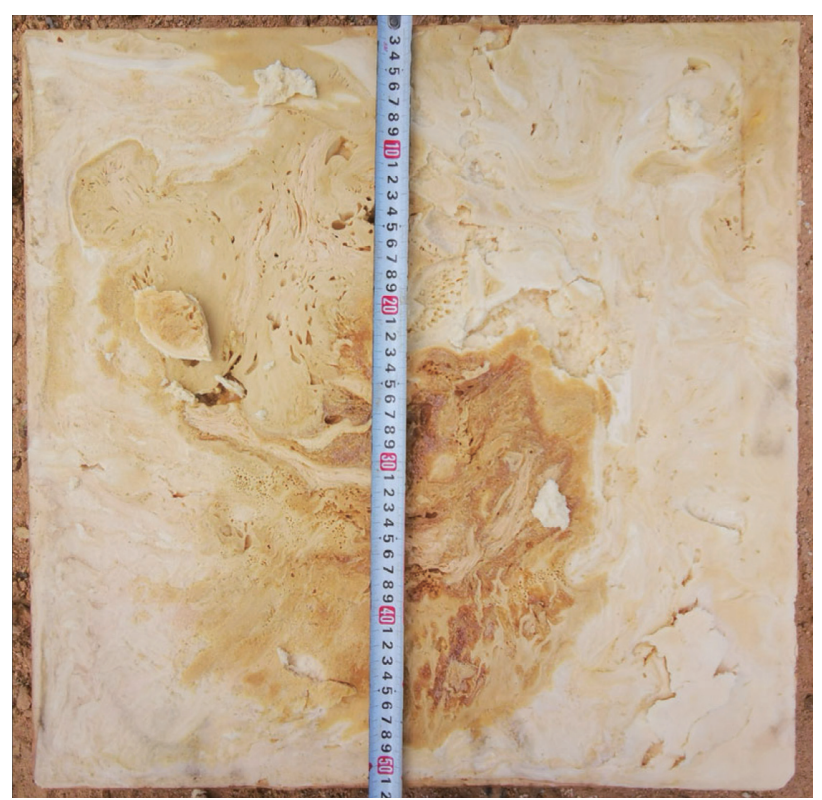

(a)

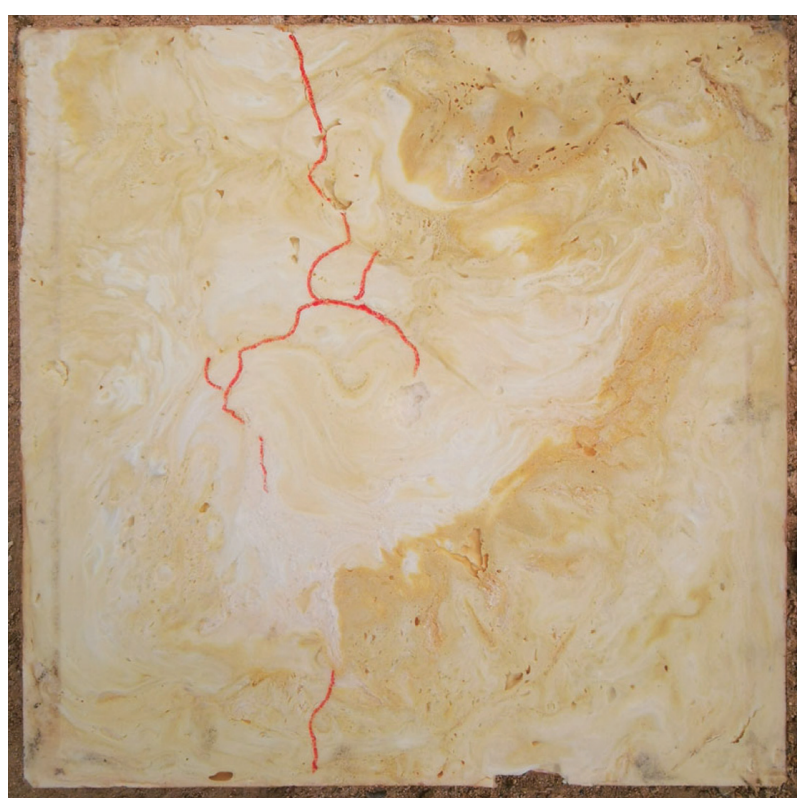

(b)

Figure 12: Test results of polymer slab B1 under $15 \mathrm{~g}$ explosive. (a) Top surface. (b) Bottom surface.

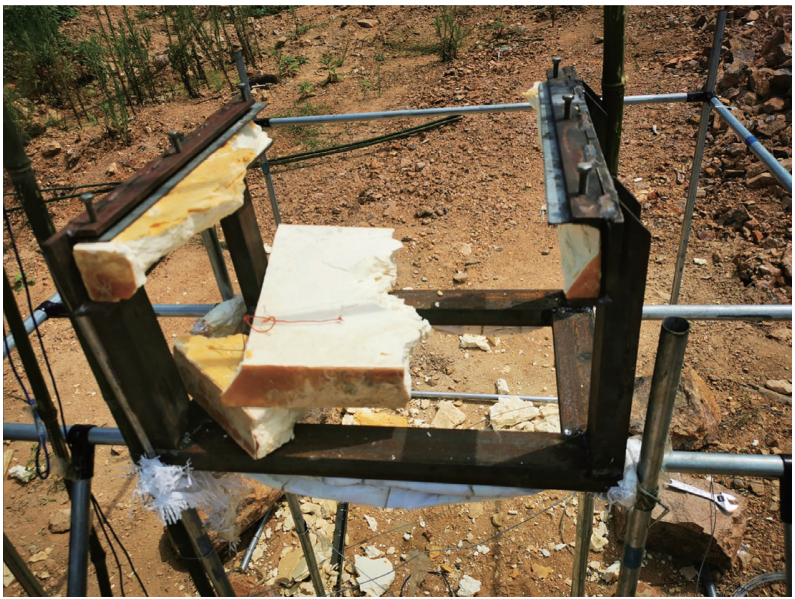

(a)

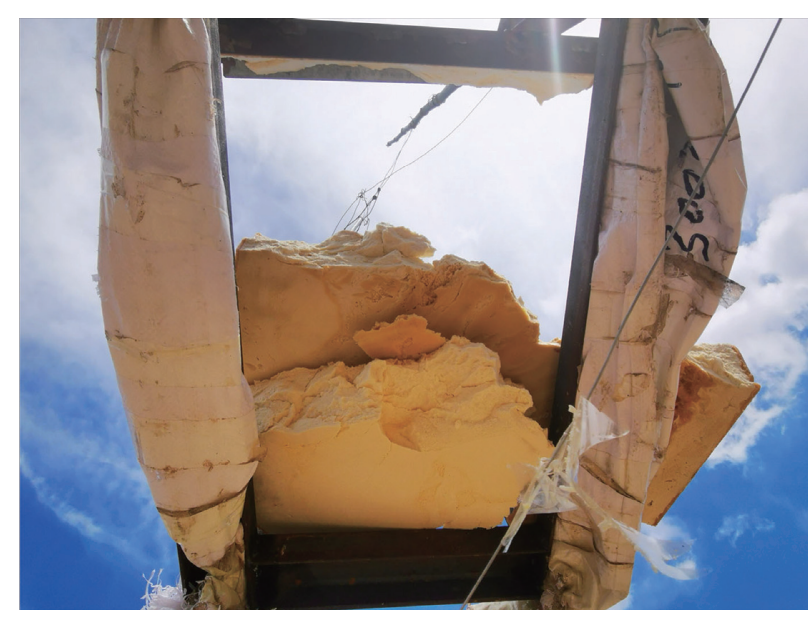

(b)

FIgURe 13: Test results of polymer slab B2 under $25 \mathrm{~g}$ explosive. (a) Top surface. (b) Bottom surface.

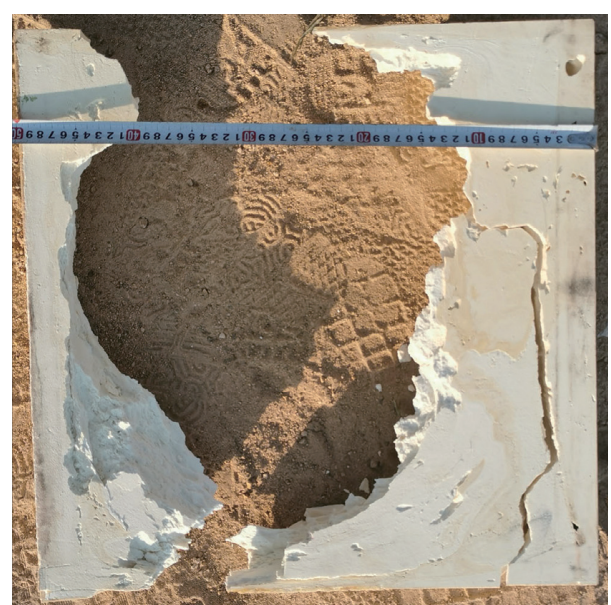

(a)

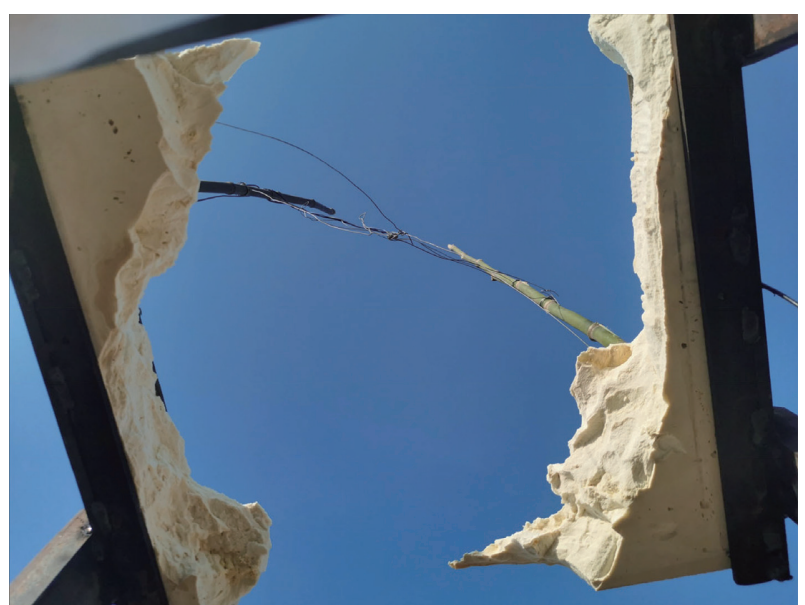

(b)

FIgURE 14: Test results of polymer slab B3 under $30 \mathrm{~g}$ explosive. (a) Top surface. (b) Bottom surface. 


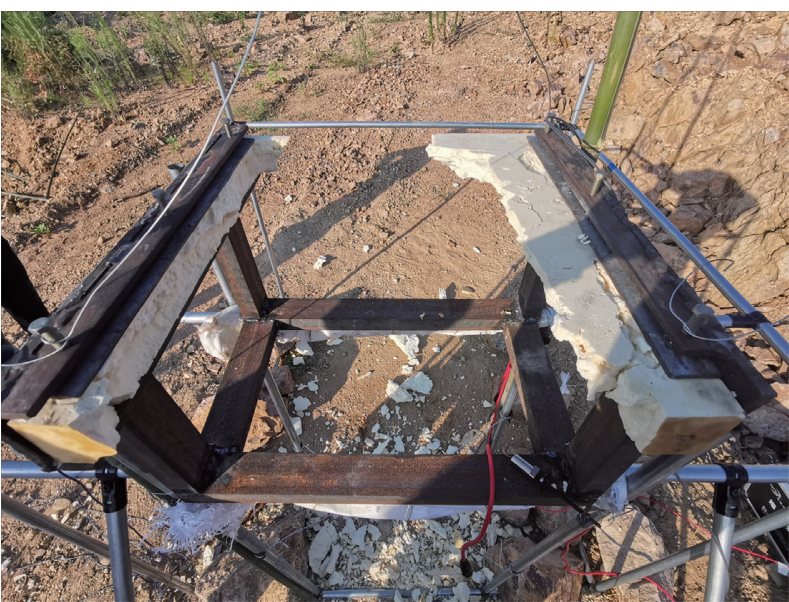

(a)

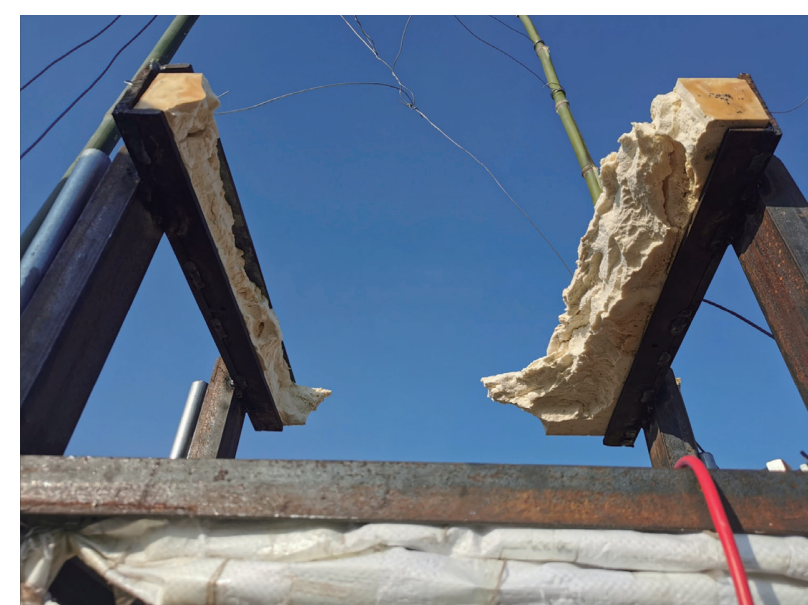

(b)

Figure 15: Test results of polymer slab B4 under $50 \mathrm{~g}$ explosive. (a) Top surface. (b) Bottom surface.

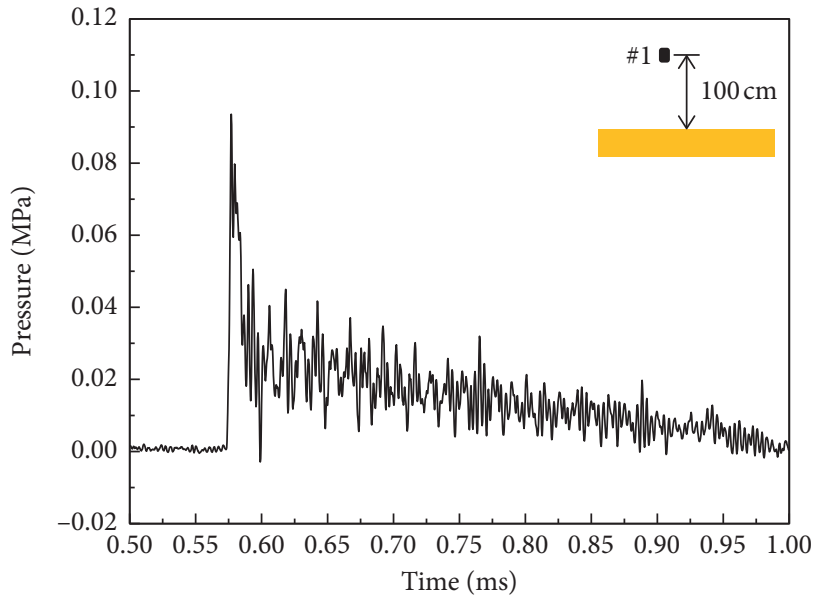

(a)

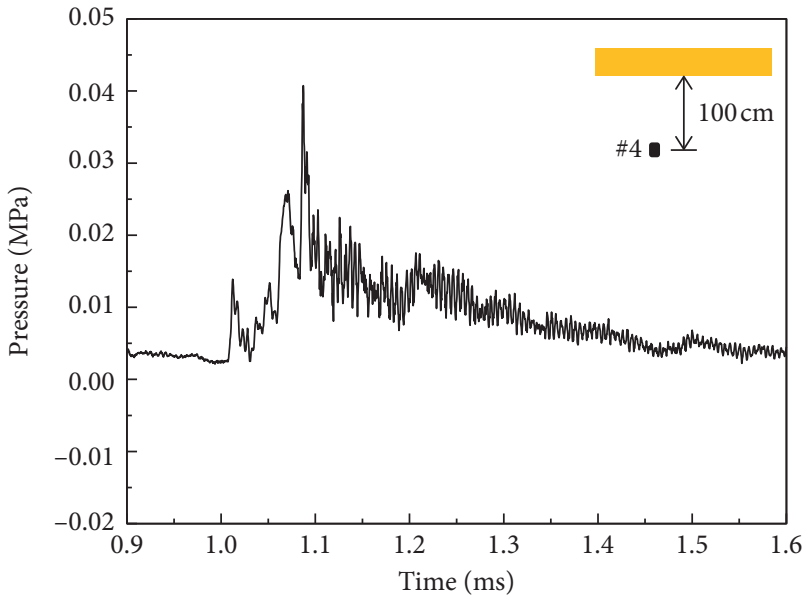

(b)

FIgURE 16: Time history curves of shock wave pressure in slab B1. Air shock wave measured using (a) sensor \#1 and (b) sensor \#4.

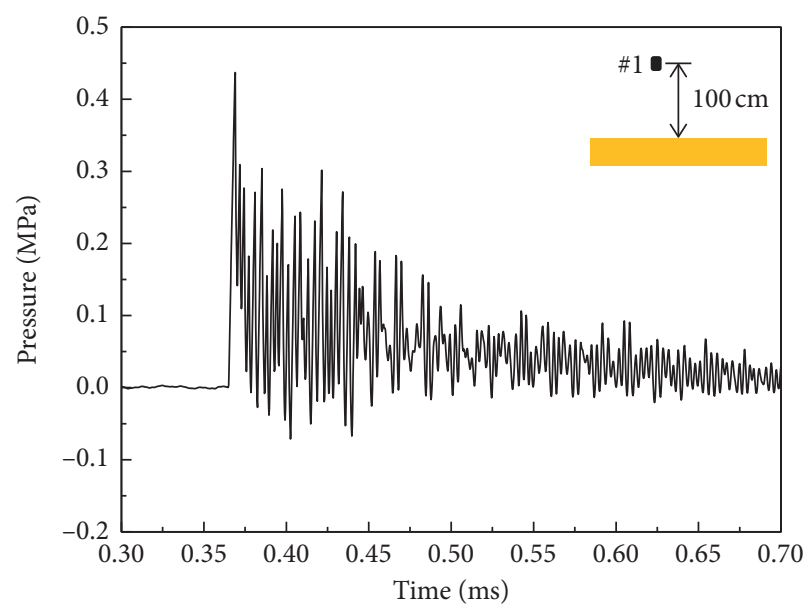

(a)

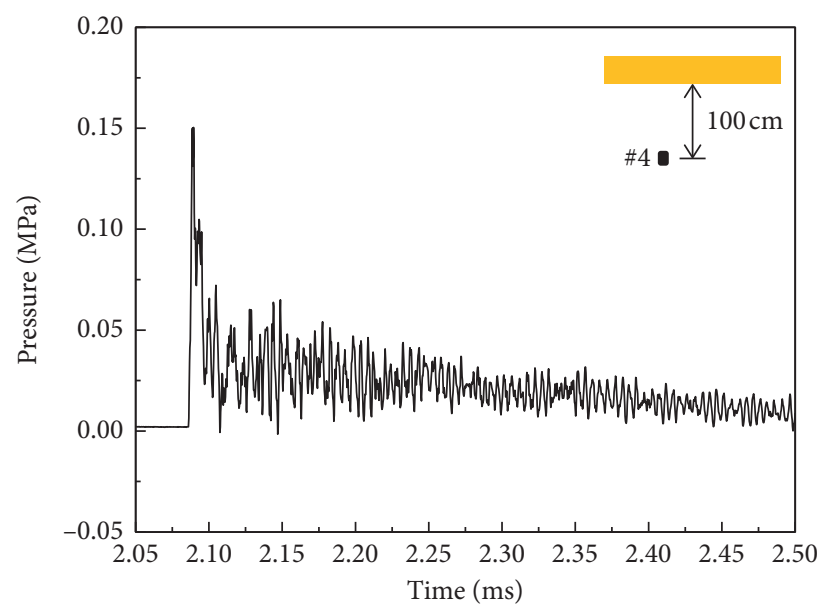

(b)

Figure 17: Time history curves of shock wave pressure in slab B3. Air shock wave measured using (a) sensor \#1 and (b) sensor \#4. 


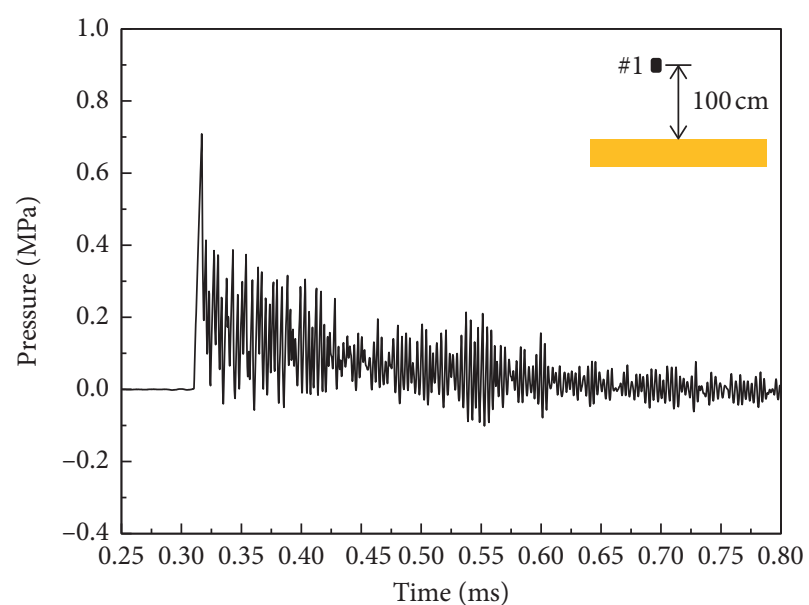

(a)

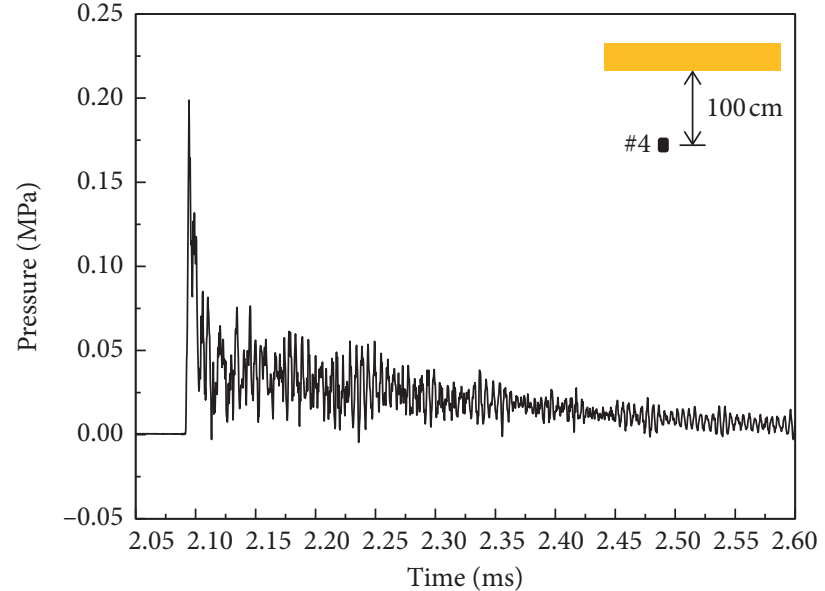

(b)

FIGURE 18: Time history curves of shock wave pressure in slab B4. Air shock wave measured using (a) sensor \#1 and (b) sensor \#4.

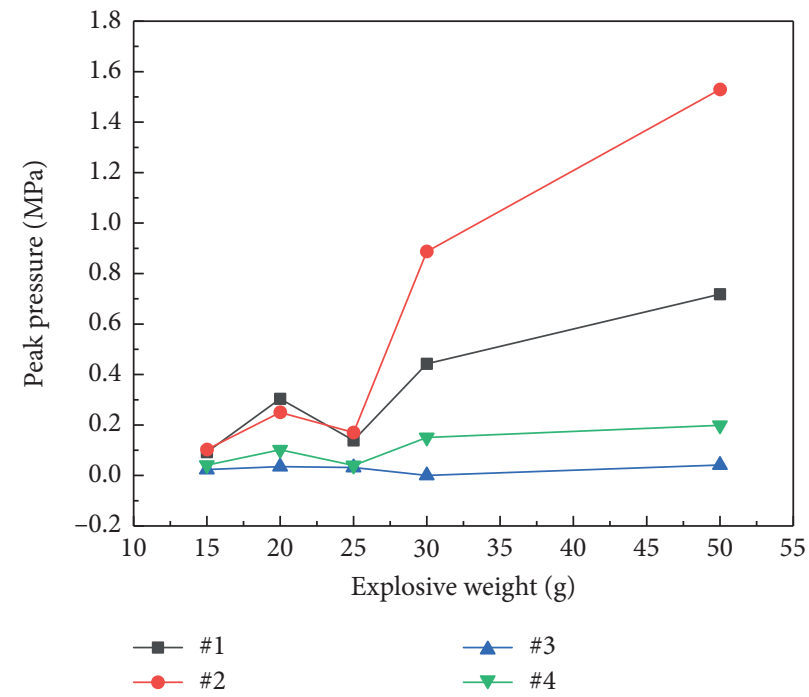

FIGURE 19: The peak pressure under close-in explosions with different explosive mass.

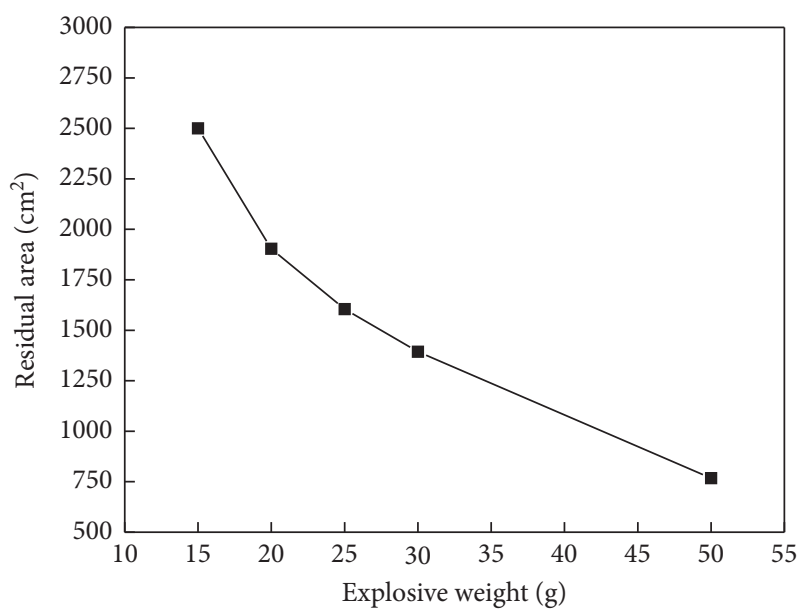

Figure 20: Residual area of polymer slab under close-in explosion. 


\section{Conclusions}

In this study, the failure modes of polymer slabs under the impact of air contact and close-in explosions were studied by field explosion tests. The effects of standoff distance and charge weight were studied. The propagation characteristics of the shock wave were also compared and analyzed. The following conclusions can be drawn:

(1) Under the same explosive charge weight, the damage degree of polymer slab under close-in explosion is more serious than that with contact explosion. For contact explosion, the polymer slab is mainly damaged locally, and penetrating damage is formed in the center of the slab. Under the action of close-in explosion, the polymer slab is mainly damaged as a whole, resulting in serious fracture.

(2) The damage degree of the polymer slab becomes larger as the explosive quality increases. The failure mode of the specimen changes from cracking failure to penetrating failure and then to overall failure.

(3) The polymer slab has a certain weakening effect on the shock wave generated by the contact and close-in explosions. Under close-in explosion, as the explosive charge weight increases, the weakening effect of the polymer slab is enhanced within a certain range.

\section{Data Availability}

The data used to support the findings of this study are available from the corresponding author upon request.

\section{Conflicts of Interest}

The authors declare that they have no conflicts of interest.

\section{Acknowledgments}

The authors gratefully appreciate the supports from the National Natural Science Foundation of China (52009126), Key Scientific Research Projects of Colleges and Universities in Henan Province (21A570006), the Outstanding Young Talent Research Fund of Zhengzhou University (1621323001), and China Postdoctoral Science Foundation (2020M672311 and 2020T130569).

\section{References}

[1] M. Li, M. Du, F. Wang et al., "Study on the mechanical properties of polyurethane (PU) grouting material of different geometric sizes under uniaxial compression," Construction and Building Materials, vol. 259, Article ID 119797, 2020.

[2] S. Saleh, N. Z. M. Yunus, K. Ahmad, and N. Ali, "Improving the strength of weak soil using polyurethane grouts: a review," Construction and Building Materials, vol. 202, pp. 738-752, 2019.

[3] H. Fang, Y. Su, X. Du, F. Wang, and B. Li, "Experimental and numerical investigation on repairing effect of polymer grouting for settlement of high-speed railway unballasted track," Applied Sciences, vol. 9, no. 21, Article ID 4496, 2019.
[4] H. Fang, B. Li, F. Wang, Y. Wang, and C. Cui, "The mechanical behaviour of drainage pipeline under traffic load before and after polymer grouting trenchless repairing," Tunnelling and Underground Space Technology, vol. 74, pp. 185-194, 2018.

[5] R. Wang, F. Wang, J. Xu, Y. Zhong, and S. Li, "Full-scale experimental study of the dynamic performance of buried drainage pipes under polymer grouting trenchless rehabilitation," Ocean Engineering, vol. 181, pp. 121-133, 2019.

[6] F. Wang, C. Guo, and Y. Gao, "Formation of a polymer thin wall using the level set method," International Journal of Geomechanics, vol. 14, 2013.

[7] S. R. Iyengar, E. Masad, A. K. Rodriguez, H. S. Bazzi, D. Little, and H. J. M. Hanley, "Pavement subgrade stabilization using polymers: characterization and performance," Journal of Materials in Civil Engineering, vol. 25, no. 4, pp. 472-483, 2013.

[8] C. Guo, C. Cui, and F. Wang, "Case study on quick treatment of voids under airport pavement by polymer grouting," Journal of Materials in Civil Engineering, vol. 32, Article ID 05020006, 2020.

[9] A. Chaudhari, V. Gite, S. Rajput, and P. Mahulikar, "Development of eco-friendly polyurethane coatings based on neemoil polyetheramide," Industrial Crops and Products, vol. 50, pp. 550-556, 2013.

[10] M. Shi, F. Wang, and J. Luo, "Compressive strength of polymer grouting material at different temperatures," Journal of Wuhan University of Technology-Materials Science Edition, vol. 25, no. 6, pp. 962-965, 2010.

[11] M. Li, H. Fang, M. Du, C. Zhang, Z. Su, and F. Wang, "The behavior of polymer-bentonite interface under shear stress," Construction and Building Materials, vol. 248, Article ID 118680, 2020.

[12] I. Beverte, "An experimental method for the investigation of rigid polyurethane foams in shear," Journal of Cellular Plastics, vol. 54, no. 5, pp. 851-884, 2018.

[13] H. Fang, Z. Su, X. Li, F. Wang, and Y. Fu, "Interfacial bond performance between self-expansion polymer and concrete," Construction and Building Materials, vol. 270, Article ID 121459, 2020.

[14] D. Niedziela, I. E. Ireka, and K. Steiner, "Computational analysis of nonuniform expansion in polyurethane foams," Polymers, vol. 11, no. 1, Article ID 100, 2019.

[15] M. Hao, F. Wang, X. Li, and B. Zhang, "Numerical and experimental studies of diffusion law of grouting with expansible polymer," Journal of Materials in Civil Engineering, vol. 30, Article ID 0002130, 2017.

[16] F. Wang, M. Shi, H. Li, and Y. H. Zhong, "Experimental study on the anti-permeability properties of polymer grouting materials," Advanced Materials Research, vol. 284-286, pp. 1952-1955, 2011.

[17] J. Chen, X. Yin, H. Wang, and Y. Ding, "Evaluation of durability and functional performance of porous polyurethane mixture in porous pavement," Journal of Cleaner Production, vol. 188, pp. 12-19, 2018.

[18] W. Wang, D. Zhang, F. Lu, S. Wang, and F. Tang, "Experimental study and numerical simulation of the damage mode of a square reinforced concrete slab under close-in explosion," Engineering Failure Analysis, vol. 27, pp. 41-51, 2013.

[19] X. Zhao, G. Wang, W. Lu, and Y. Guangdong, "Experimental investigation of RC slabs under air and underwater contact explosions," European journal of environmental and civil engineering, vol. 25, pp. 1-15, 2018. 
[20] A. Dua and A. Braimah, "Assessment of reinforced concrete slab response to contact explosion effects," Journal of Performance of Constructed Facilities, vol. 34, no. 4, Article ID 04020061, 2020.

[21] Y. Gao, Y. Zhou, J. Zhou et al., "Blast responses of one-way sea-sand seawater concrete slabs reinforced with BFRP bars," Construction and Building Materials, vol. 232, Article ID 117254, 2020.

[22] J. Li, C. Wu, H. Hao, and Y. Su, "Experimental and numerical study on steel wire mesh reinforced concrete slab under contact explosion," Materials \& Design, vol. 116, pp. 77-91, 2017.

[23] Y.-S. Chen, B. Wang, B. Zhang et al., "Polyurea coating for foamed concrete panel: an efficient way to resist explosion," Defence technology, vol. 16, no. 1, pp. 136-149, 2020.

[24] G. Yang, G. Wang, W. Lu, L. Wu, P. Yan, and M. Chen, "Experimental and numerical study of damage characteristics of RC slabs subjected to air and underwater contact explosions," Marine Structures, vol. 66, pp. 242-257, 2019.

[25] T.-S. Zhuang, M.-Y. Wang, J. Wu, C.-Y. Yang, T. Zhang, and C. Gao, "Experimental investigation on dynamic response and damage models of circular RC columns subjected to underwater explosions," Defence Technology, vol. 16, no. 4, pp. 856-875, 2020.

[26] J. Yang, J. Dai, C. Yao, J. Shuihua, Z. Chuangbing, and J. Qinghui, "Estimation of rock mass properties in excavation damage zones of rock slopes based on the Hoek-Brown criterion and acoustic testing," International Journal of Rock Mechanics and Mining Sciences, vol. 126, Article ID 104192, 2020.

[27] J. Yang, J. Cai, C. Yao, P. Li, Q. Jiang, and C. Zhou, "Comparative study of tunnel blast-induced vibration on tunnel surfaces and inside surrounding rock," Rock Mechanics and Rock Engineering, vol. 52, no. 11, pp. 4747-4761, 2019. 